\title{
Analysis of polyaromatic hydrocarbon (PAH) contaminated riparian sediment and source identification
}

\author{
K. L. Rowberg ${ }^{1} \&$ J. T. Smith ${ }^{2}$ \\ ${ }^{I}$ Department of Chemistry, Purdue University Calumet, USA \\ ${ }^{2}$ Cargill, USA
}

\begin{abstract}
Sediment in the Grand Calumet River, Indiana, USA was analyzed for criterion polyaromatic hydrocarbons (PAHs). The sediment was freeze dried, extracted with methylene chloride using a Soxhlet apparatus, and followed by Florisil clean up. Gas chromatography/mass spectrometry was used to separate and characterize the PAHs. Of the United States priority pollutants for PAH, the major contaminant was chrysene. Other priority PAH contaminants detected were pyrene, benzo[b]fluoranthene, benzo[a]anthracene, benzo $(\mathrm{g}, \mathrm{h}, \mathrm{i})$ perylene, phenanthrene, and fluoranthene.

Three methyl-substituted PAHs were detected in the sediment. 5-methylchrysene is used to examine possible source of contaminant and weathering time.
\end{abstract}

Keywords: polyaromatic hydrocarbon, toxicity, phototoxicity, chrysene, dredging, contaminant source, weathering.

\section{Introduction}

Dredging of contaminated river sediment in northwest Indiana is proposed for economic and health reasons. Barges can navigate the waterways with only partial loads and, therefore, shipping time increases. The sediments in the waterways contain heavy metals, polynuclear aromatic hydrocarbons (PAHs), and polychlorinated biphenyls among other pollutants [1]. PAHs concentrate in sediment three orders of magnitude greater than surface waters [2]. The Grand Calumet Harbor contains the highest levels of PAH-contaminated sediment in the Great Lakes system [3]. The waterways flow into Lake Michigan where 
water intakes supply drinking water. Some PAHs are toxic and cause DNA mutations leading to tumor growth in humans.

While the need for dredging is apparent, the effect of disturbing the contaminated sediments is unknown. PAHs are typically hydrophobic and bind to the sediment matrix. As a precautionary measure, curtains may be installed to allow settling of suspended sediment before the water flows into Lake Michigan.

The dredged sediment will be placed in a confined disposal facility. The PAHs will remain bound to the sediment due to the hydrophobic nature of PAHs. Where sediment becomes exposed to the atmosphere, PAHs will largely remain bound to the sediment due to the semi-volatile nature of the PAHs.

In general, solar ultra-violet radiation does not penetrate very far into the water column. However, in the confined disposal facility, the sediments will be covered with minimal water or be exposed to atmospheric conditions. Some PAHs are photoactivated by solar irradiation and may become phototoxic to aquatic organisms [4]. The phototoxic effects of PAHs in the confined disposal facility are unknown.

In addition to mobility and phototoxicity of PAHs, PAHs react in aqueous solutions to form substituted-PAHs. Radner produced nitro-naphthalenes in aqueous solutions of dinitrogen teroxide [5]. Vione and coworkers produced nitronaphthalenes in aqueous nitrate solutions when irradiated [2]. Vione also produced nitro-and hydroxy-benzene from nitrite/nitrous acid solutions [6]. Naka and coworkers produced aniline from nitrobenzene and iron(II)-catechol complexes [7]. Ross and coworkers isolated dihydroxy-metabolites from aqueous solutions of pyrene, phenanthrene and fluoranthene and a strain of Mycobacterium flavescens [8]. The possible impact of derivatives is not completely known.

Weathering of PAHs alters the composition of oil sludges. Alkylated naphthalenes, phenanthrenes, and chrysenes ratios are used to assess the extent of weathering in oil spills [9] and the ratio is applied to a first approximation to an oily river sediment.

\section{Method of PAH analysis in contaminated sediments}

A sediment sample from the Grand Calumet River, Indiana was obtained from a manual core sampler. Approximately $15 \mathrm{~cm}$ of the top sediment (oily muck) were place in a brown glass bottle and refrigerated for nearly six months. Pebbles were removed prior to freeze drying. The sample was freeze dried in a UNITOP model $880 \mathrm{~L}$ at $-68^{\circ} \mathrm{C}$ and 300 motor vacuum for three days.

The resulting powder was ground with a mortar and pestle and remixed. The sample was mixed with $2 \mathrm{~g}$ anhydrous sodium sulfate and spiked with hexamethyl benzene. Between 10 and $20 \mathrm{~g}$ of sample was weighed into an extraction thimble and placed in a Soxhlet apparatus. The Soxhlet apparatus was attached to a condenser and a round bottom flask containing $130 \mathrm{ml}$ of methylene chloride. The temperature of the sand bath was adjusted to maintain reflux of the solvent for eight hours. 
The extract was concentrated in a rotary evaporator with dry ice/acetone condenser with a $30^{\circ} \mathrm{C}$ water bath. A slight vacuum was applied until the extract was approximately $0.5 \mathrm{ml}$. The extract was combined with $2 \mathrm{~g}$ of sodium sulfate and remaining methylene chloride was purged under a gentle stream of nitrogen. The resulting extract was dark yellow.

A 1.2-cm glass chromatography column was slurry packed with $3 \mathrm{~g}$ of activated Florisil in hexane. The extract was loaded onto the column with two $1-\mathrm{ml}$ aliquots of hexane. The column was eluted with $15 \mathrm{ml}$ of hexane followed by $25 \mathrm{ml}$ of 1:1 hexane/methylene chloride mixture. The eluent was concentrated to approximately $0.5 \mathrm{ml}$ by adding $2 \mathrm{ml}$ of toluene as a keeper. The eluent was quantitatively transferred to a $10-\mathrm{ml}$ volumetric flask and diluted.

The eluent sample $(1 \mu \mathrm{l})$ was injected on a $30-\mathrm{m}$ Supelco PTE-5 column with inner diameter of $0.25 \mu \mathrm{m}$ attached to the Hewlett Packard gas chromatograph/mass spectrometer port. The initial settings were $300^{\circ} \mathrm{C}$ inlet temp, $320^{\circ} \mathrm{C}$ detector temp, split injection, $325^{\circ} \mathrm{C}$ max column temp, $100^{\circ} \mathrm{C}$ initial temp, $4.0 \mathrm{~min}$ initial hold time increasing to $200^{\circ} \mathrm{C}$ at $5^{\circ} / \mathrm{min}$ with hold of $3 \mathrm{~min}$, then increasing to $250^{\circ} \mathrm{C}$ at $8 \% \mathrm{~min}$ with hold of $5 \mathrm{~min}$, and finally increasing to $300^{\circ} \mathrm{C}$ at $12^{\circ} / \mathrm{min}$ and hold for $10 \mathrm{~min}$.

Each peak on the chromatogram was identified by matching retention time and fragment analysis to mass spectrometer patterns from the Hewlett Packard database. A series of standards were used to establish the retention times of the sixteen priority pollutants on the column used.

\section{Results}

GC/MS was used to separate and identify PAH pollutants in sediment. The eluent from the sediment contained seven of the United States Environmental Protection Agency priority pollutants for PAHs that attained above 93\% match with the mass spectroscopy fragment library: chrysene, pyrene, benzo[b]fluoranthene, benzo[a]anthracene, benzo(g,h,i)perylene, phenanthrene, and fluoranthene. Of these, chrysene was the major constituent. The relative amounts of these contaminants are found in Table 1.

Table 1: $\quad$ Relative amounts of priority PAH contaminants.

\begin{tabular}{|l|l|}
\hline $\begin{array}{c}\text { PAH } \\
\text { Criterion Contaminant }\end{array}$ & $\begin{array}{l}\text { Amount relative to } \\
\text { chrysene (\% ratio) }\end{array}$ \\
\hline Chrysene & 100 \\
\hline Pyrene & 30.5 \\
\hline Benzo[b]fluoranthene & 30.2 \\
\hline Benz[a]anthracene & 27.8 \\
\hline Benzo[a]pyrene & 18.7 \\
\hline Benzo(g,h,i)perylene & 17.0 \\
\hline Phenanthrene & 12.9 \\
\hline
\end{tabular}


PAHs other than the priority pollutants were present. Of note are three methyl-substituted PAHs present in relative high concentrations (see Figure 1 for structures and Table 2 for relative amounts).

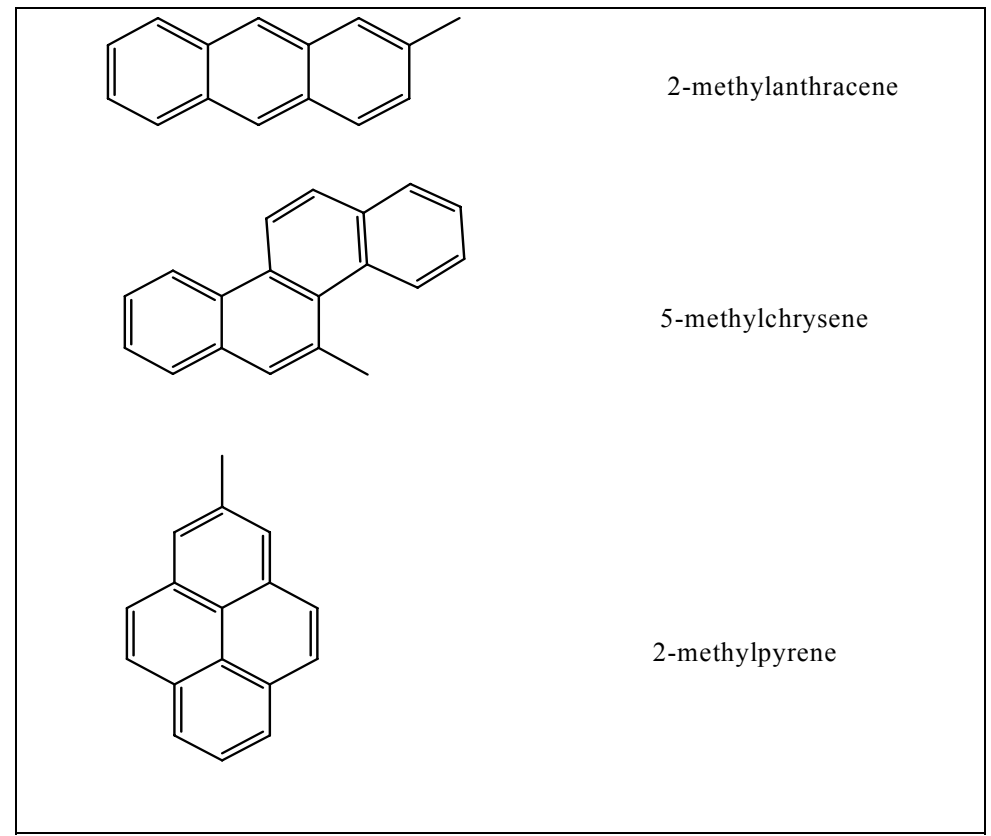

Figure 1: $\quad$ Structures of methyl-substituted PAHs.

Table 2: $\quad$ Relative amounts of methyl-substituted PAHs.

\begin{tabular}{|l|l|}
\hline PAH Contaminant & $\begin{array}{l}\text { Amount relative to } \\
\text { chrysene (\% ratio) }\end{array}$ \\
\hline Chrysene & 100 \\
\hline 5-methylchrysene & 52.7 \\
\hline 2-methylpyrene & 21.0 \\
\hline 2-methylanthracene & 14.5 \\
\hline
\end{tabular}

\section{Discussion}

Sediment samples collected in 1985 from the waterways of Indiana that flow into Lake Michigan showed elevated levels of several PAH compounds. Some samples exhibited very high level in comparison to other Great Lake sediments [1]. The sediment sample for this study was collected from the Roxana Marsh in the Grand Calumet River, East Chicago, Indiana, USA. The seven priority PAHs were: chrysene, pyrene, benzo[b]fluoranthene, benzo[a]anthracene, benzo(g,h,i)perylene, phenanthrene, and fluoranthene. 
Weathering of oil occurs through chemical, physical, and biological processes. In river sediments, it is likely that biological processes are the major method of weathering with nutrients being the limiting factor. Typically 2- and 3-ring PAHs (such as naphthalene, anthracene and phenanthrene) are degraded more rapidly than larger PAHs. Although Short and coworkers report a higher proportion of methylchrysene to the parent chrysene in marine and riverine sediments [12], the Grand Calumet River sample had a lower proportion. This may be due to enhanced biodegradation of the methyl-substituted PAH.

Incineration elevates concentrations of large polycyclic aromatic compounds, such as unsubstituted and 4- to 6-ring PAHs[9]. Chrysene, a 4-ring PAH, is recalcitrant to degradation [9]. Chrysene is the most abundant $\mathrm{PAH}$ in the sediment sample. The prominence of chrysene and other 5-ring PAHs in the $\mathrm{PAH}$ profile is indicative of a coal origin [11]. Although no identification of the source is attempted, several industries burned coal as an energy source.

\section{Conclusion}

The sediments in the Indiana Harbor and Grand Calumet River are contaminated to some of the highest levels measured in the Great Lakes Region. The waterways are part of Lake Michigan Basin, and, therefore, aqueous contaminants ultimately enter Lake Michigan. PAHs bind well to sediments are hydrophobic, therefore the concentration of PAHs in river and lake waters is low. Even at low concentrations, some PAHs (especially those larger than naphthalene) are toxic and/or phototoxic. It is possible for PAHs to react in aqueous media to form compounds with nitro, hydroxyl, or amino substituents. These compounds will be more hydrophilic with the polar substituents, and, therefore increasingly water soluble. Of concern is possible increased toxicity and phototoxicity.

The sediment sample from the Grand Calumet River was contaminated with eleven of the priority pollutants: phenanthrene, fluoranthene, pyrene, benz[a]anthracene, chrysene, benzo[b]anthracene, and benzo(g,h,i)perylene. Of these, chrysene was the major constituent. The abundance of chrysene and other 5-ring PAHs suggest a coal origin of the PAHs in the sediment.

\section{References}

[1] US Army Corps of Engineers (eds). Indiana Harbor and Canal Maintenance Dredging and Disposal Activities. Comprehensive Management Plan, United States Environmental Protection Agency: Chicago, 1998.

[2] Vione, D., Maurino, V., Minero, C. \& Pelizzetti, E., Nitration and photonitration of naphthalene in aqueous systems. Environ. Sci. Technol., 39(4), pp. 1101-1110, 2005.

[3] Eadie, B.J., Distribution of PAH in the Great Lakes, Toxic Contaminants in the Great Lakes, ed. J.O. Nriagu and M.S. Simmons, J. Wiley and Sons: New York, pp. 195-211, 1984. 
[4] Davenport, R., \& Spacie, A., Acute Phototoxicity of Harbor and Tributary sediments from lower Lake Michigan, J. Great Lakes Res., 17(1), pp. 5156, 1991.

[5] Radner, F., Nitration of polycyclic aromatic hydrocarbons with dinitrogen tetroxide. A simple and selective synthesis of mononitroderivatives. Acta Chem. Scand., B37, pp. 65-67, 1983.

[6] Vione, D., Maurino, V., Minero, C., \& Pelizzetti, E., Nitration and hydroxylation of benzene in the presence of nitrite/nitrous acid in aqueous solution. Chemosphere, 56, pp. 1049-1059, 2004.

[7] Naka, D., Kim, D., \& Strathmann, T.J., Abiotic reduction of nitroaromatic compounds by aqueous iron(II)-catechol complexes. Environ. Sci. Technol., 40(9), pp. 3006-3012, 2006.

[8] Dean-Ross, D., \& Cerniglia, C.E., Degradation of pyrene by Mycobacterium flavenus, Applied Microbiology and Biotechnology, 46, pp. 307-312, 1996.

[9] Douglas, G.S., Bence, A.E., Prince, R.C., McMillen, S.J., \& Butler, E.L., Environmental Stability of Selected Petroleum hydrocarbon source and weathering ratios. Environ. Sci. Technol., 30(7), pp. 2332-2339, 1996.

[10] Simpson, C.D., Cullen, W.R., Quinlan, K.B., Reimer, K.J., Methodology for the determination of priority pollutant polycyclic aromatic hydrocarbons in marine sediments. Chemosphere, 31(9), pp. 4143-4155, 1995.

[11] Short, J.W., Kvenvolden, K.A., Carlson, P.R., Hostettler, F.D., Rosenbauer, R.J., \& Wright, B.A., Natural hydrocarbon background in benthic sediments of Prince William Sound, Alaska: Oil vs. coal. Environ. Sci. Technol., 33(1), pp. 34-42, 1999. 